\begin{tabular}{|c|c|c|}
\hline 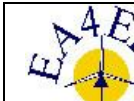 & $\begin{array}{c}\text { European Association for the } \\
\text { Development of Renewable Energies, Environment } \\
\text { and Power Quality (EA4EPQ) }\end{array}$ & $\begin{array}{l}\text { International Conference on Renewable Energies and Power Quality } \\
\text { (ICREPQ'12) } \\
\text { Santiago de Compostela (Spain), 28th to 30th March, } 2012\end{array}$ \\
\hline
\end{tabular}

\title{
High Voltage Live Works: Comparative Safe Distance Approach Calculation
}

\author{
S. Belkhir ${ }^{1}$, H. Moulai ${ }^{1}$, T. Ainouche ${ }^{1}$ and F. Soukeur ${ }^{2}$ \\ ${ }^{1}$ Laboratory of Electrical and Industrial Systems, \\ FEI, USTHB, BP 32, Bab Ezzouar, Algiers, Algeria \\ E-mail: belkhir.s@hotmail.com \\ ${ }^{2}$ National Power Grid Manager (GRTE-SONELGAZ), \\ les 500 bureaux, Gué de Constantine, Algiers, Algeria
}

\begin{abstract}
This work is devoted to a comparative study of the Safe Approach distances calculations when live works on high voltage structures are to be performed. These distances must be determined by the most rigorous way in order to ensure a total security of the operators in charge of these works. Several authors propose different empirical formulas of the statistical breakdown voltage $\mathrm{U}_{50}$ as a function of the gap $\mathrm{Du}$ in rod plane electrode configuration under normalized surge overvoltage. Safe distances to be respected in high voltage line works are determined on the basis of these statistical breakdown voltages. A comparative survey will be achieved between the proposed approaches, and their use in the minimal distance approach assessment techniques recommended by IEC $61-472$ and IEEE Std 516 standards. These techniques will be coupled with electric field numerical calculations in order to foresee an extension of these techniques to live works with non conventional tools.
\end{abstract}

\section{Key words}

High voltage structures, Safe approach distances, live works, non conventional tools.

\section{Introduction}

Electric energy consumers are more and more sensible to current cut-offs whatever is the reason. Live works can contribute to avoid these current break-ups that create annoyances to users and can also represent costs as well for power deliverers than for consumers.

Thus, producers and distributors are obligated to perform a maximum of maintenance and repairing works on overhead lines and substations while being under voltage. Safe approach distances to be respected must be determined by the most rigorous way in order to ensure a total security of the operators in charge of these works [14]. Standardised techniques have been developed in order to assess these safe distances. They are essentially described in IEEE Std 516 and IEC 61472 standards [5, $6]$ and that concern mainly the variations of these distances as a function of the line voltage level, knowing that the dielectric strength of air is very dependent on the electrode gap [7]. The only element integrating the geometry of the system is included in the gap factor $[5,6]$ that takes in account the macroscopic properties of the considered line section.

The experimental works having led to the implementation of these standards concern the breakdown switching overvoltages in a rod-plane electrode system of large dimensions, where the principal parameters are the statistical breakdown voltage and the gap [7]. The practical difficulty to lead this kind of experiences on sharp tips incited us to outline it by taking in account the electric field instead of the applied voltage. Because the breakdown conditions depend as well on the voltage level than on the geometry of the tools that are present in the area of the shortest inter-potential distance [8]; the medium being always air. Thus, the interest to take in account the electric field reigning in the vivacious area of work for the dimensioning of the MAD becomes more suitable and permits to have a precise knowledge of the maximal gradients that it can reach.

This subject is actually of more importance than live works have tendency to become more and more numerous, requiring thus, sometimes, the use of precision tools whose dimensions can be enough sharpened with regard to those commonly considered.

The peculiarity of this work consists on considering the distance and the electric field in order to take in account with a precise manner the geometric affinities of the system where will be executed an overhead live working. This advantage of the field will enable us to refine the dimensioning of the MAD while taking in account the shape and the dimensions of the floating objects often intervening in the vivacious area of work and also of the operator's morphology (human body or machine) with regard to the structure of the pylon or also to the cross arm. 
Thus, this work is oriented towards the dimensioning of safe approach distances when no conventional tools come to be used in exceptional operations of live works.

\section{Practical Considerations and Standard Techniques}

When dimensioning safe approach distances, the critical situation is considered when the line is submitted to a surge overvoltage; the case of a lightning overvoltage being excluded by the fact that live works are strictly forbidden when lightning is observed within $10 \mathrm{~km}$ of the work site.

In experimental tests and studies, among the different intervals of the same spacing $D$, the positive rod-plane gap configuration presents the weakest strength and is used as a reference by all authors [4, 7-9].

For live works, the minimum approach distance is determined with regard to the discharge voltage generated by a switching overvoltage and is expressed by:

$\mathrm{D}_{\mathrm{A}}=\mathrm{D}_{\mathrm{U}}+\mathrm{D}_{\mathrm{E}}$, where $\mathrm{D}_{\mathrm{U}}$ is the electric distance (related to the discharge voltage) and $\mathrm{D}_{\mathrm{E}}$ the ergonomic distance (involuntary movements of the operator) figure1).

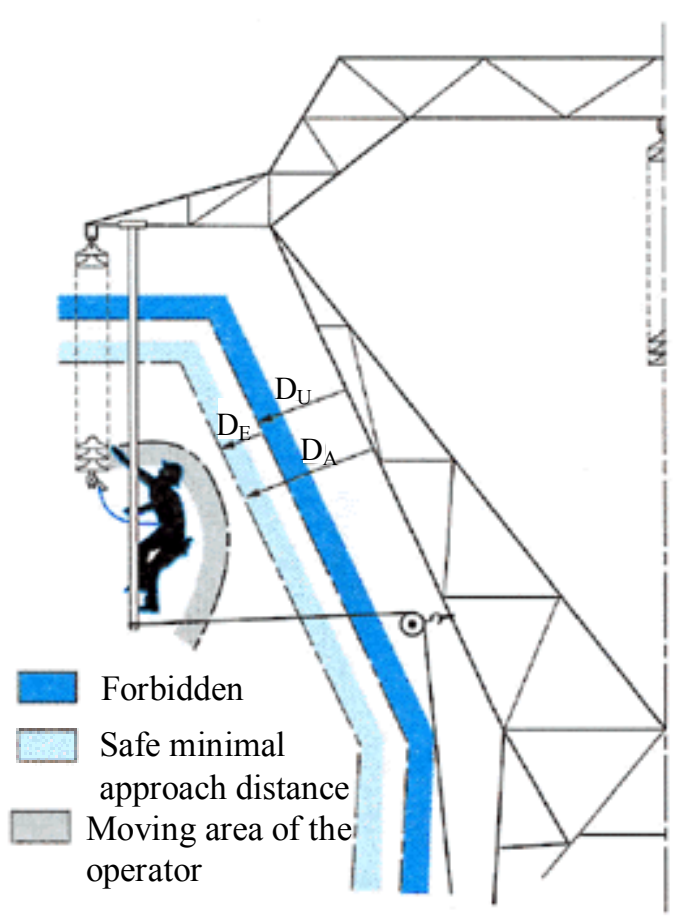

Fig. 1. Sketch of the safe live work at the line potential.

\section{A. IEC 61-472 Standard}

Surge overvoltage amplitudes depend on the performances of the circuit breaker and on the electric characteristics of the line. Also, it varies from a network to the other.

The safety electric distance is determined from the statistical overvoltage at $2 \% \mathrm{U}_{\mathrm{e} 2}$ which is an overvoltage having a probability of $2 \%$ to be overtaken, and from which the minimum approach distance can be determined. Overvoltages must be either measured or determined by studies on a network transient analyzer or on computer. Such studies don't provide the statistical overvoltages (value to $2 \%$ ) but only truncated values without knowledge of the statistical distribution of the typical values of the statistical overvoltage to be used when no other value is available.

\section{B. Parameters intervening in the calculations}

\section{1) Statistical overvoltage}

The electric constraint in the working area must be known. It is characterized by the statistical overvoltage that can exist in the working area. In a three phase alternating network, the statistical overvoltage $\mathrm{U}_{\mathrm{e} 2}$ between the phase and earth is:

$$
U_{e 2}=\frac{\sqrt{2}}{\sqrt{3}} \cdot U_{s} \cdot u_{e} 2
$$

Where

Us : The higher value of the network voltage;

$\mathrm{u}_{\mathrm{e} 2}$ : The statistical phase-to-earth overvoltage expressed per unit.

\section{2) Withstand voltage}

For the calculation of the minimum approach distance, the required withstand voltage for live working is taken equal to the $\mathrm{U}_{90}$ voltage which is determined from the general expression:

$\mathrm{U}_{90}=\mathrm{K} \cdot \mathrm{U}_{2}$

While considering separately the phase-to-earth and phase-to-phase voltages and by combining equations (1) and (2), one obtains:

$$
U_{e 90}=K \times \frac{\sqrt{2}}{\sqrt{3}} \cdot U_{s} \cdot u_{e 2}
$$

$\mathrm{K}$ : is a safety statistical parameter (a value of 1.1 is recommended by IEC Std).

$\mathrm{U}_{\mathrm{e} 90}$ is a statistical phase-to-earth withstand voltage.

Since we consider a phase-pylon connected to earth risk, a value of $\mathrm{u}_{\mathrm{e} 2}=2.2$ is taken.

\section{Distance $d_{u}$ Calculation}

\section{A. Calculation according to IEC 61-472 Standard}

Among the different intervals of the same spacing D, the rod-plane electrode configuration in positive polarity presents the weakest strength and is used as a reference.

The EIC 61-472 standard used for rod-plane gaps with interval spacing until $25 \mathrm{~m}$ and an overvoltage of slow front wave (Switching overvoltage), the dielectric strength $\mathrm{U}_{50 \mathrm{RP}}$ is expressed by the following empirical relation [6]:

$$
\mathrm{U}_{50 \mathrm{RP}}=1080 \mathrm{Ln}\left(0.46 \mathrm{D}_{\mathrm{U}}+1\right)
$$

Where $\mathrm{U}_{50 \mathrm{RP}}$ is the surge overvoltage having $50 \%$ of probability to trigger a breakdown in normal conditions $\left(\mathrm{kV}\right.$ crest) and $\mathrm{D}_{\mathrm{U}}$ the electric distance in meters.

For other configurations and to take in account other influences, one uses the statistical withstand voltage $\mathrm{U}_{90}$ 
that can be determined while applying the coefficient $\mathrm{Kt}$ as follows:

$$
\mathrm{U}_{90}=\mathrm{Kt} \mathrm{U}_{50 \mathrm{RP}}
$$

$\mathrm{U}_{90}$ is the overvoltage at which the insulation exhibits a $90 \%$ probability of withstand.

$$
\mathrm{U}_{90}=\mathrm{Kt} 1080 \mathrm{Ln}(0.46 \mathrm{Du}+1)
$$

Where $\mathrm{Kt}=\mathrm{Ks} * \mathrm{Kg} * \mathrm{Kf} * \mathrm{Ka} * \mathrm{Ki}$

Where $\mathrm{Ks}$ is the conventional deviation factor; $\mathrm{Kg}$ the gap factor, $\mathrm{Kf}$ the floating object factor, $\mathrm{Ka}$ the atmospheric factor and $\mathrm{Ki}$ the insulator chain factor.

By transforming equation (6), one determines the electric distance Du:

$$
\mathrm{D}_{\mathrm{U}}=2.17\left[\exp \left(\mathrm{U}_{90} / 1080 \mathrm{Kt}\right)-1\right]
$$

\section{B. Calculation according to IEEE Standard 516}

In 1968, the IEEE committee on 'Recommendations for the maintenance in security during live works" had published empirical relationships that enable the electric distance dimensioning, for various ranges of maximal transient overvoltage [5].

1) Calculation of the electric distance (Du) Phaseto-Earth without Tools in Air for Voltages greater than $72.5 \mathrm{kV}$.

The general relationship to determine the MAD (in meters) in a phase-to-earth configuration under $60 \mathrm{~Hz}$ voltages above $72.5 \mathrm{kV}$, for live works without tools in air, is indicated in equation 8 [5]:

$$
\mathrm{Du}=0.3048\left[\left(\mathrm{C}_{1}+\mathrm{a}\right)\left(\mathrm{U}_{\mathrm{e} 2}\right)\left(\mathrm{V}_{\mathrm{P}-\mathrm{G}}\right)\right]
$$

Where:

0.3048 is a conversion factor to convert feet in meters, Du is the phase-to-earth electric distance in meters, $\mathrm{C}_{1}$ is used to obtain the distances in feet.

For voltages above $50 \mathrm{kV}, \mathrm{C}_{1}=0,01(1,0 \%$ of the phaseto-earth voltage in $\mathrm{kV}$ ) for $60 \mathrm{~Hz}$.

$\mathrm{a}$ : is a factor of crest voltage for $630 \mathrm{kV}$ and more.

The values of "a" are calculated according to data obtained from reference materials. The saturation factor "a" is equal to zero when the statistical overvoltage $\left(\mathrm{U}_{\mathrm{e} 2}\right)$ is lower than $630 \mathrm{kV}$.

* For a statistical crest voltage between 630 and $1025 \mathrm{kV}$, $\mathrm{a}=\left(\left(\mathrm{U}_{\mathrm{e} 2}\right)-630\right)$ rounded to $10^{-4} / 140000$

* For a statistical crest voltage above $1025 \mathrm{kV}$, $\mathrm{a}=\left(\left(\mathrm{U}_{\mathrm{e} 2}\right)-683\right)$ rounded to $10^{-4} / 124440$

With: $\mathrm{U}_{\mathrm{e} 2}=\mathrm{V}_{\mathrm{P}-\mathrm{G}} \cdot(2 / 3)^{1 / 2} \cdot \mathrm{u}_{\mathrm{e} 2}$

$\mathrm{u}_{\mathrm{e} 2}$ : is the foreseen maximal value per overvoltage unit. $\mathrm{V}_{\mathrm{P}-\mathrm{G}}$ : is the phase-to-earth voltage in kilovolts.

\section{2) Calculation of the MAD, Phase-to-Earth, with} Tools in Air for Voltages greater than $72.5 \mathrm{kV}$.

The general formula to determine the MAD, $60 \mathrm{~Hz}$, phase-to-earth, in meters above $72.5 \mathrm{kV}$ for live works, with tools in the air gap, is specified in equation 9 [5]:

$$
\mathrm{Du}=0.3048\left[\left(\left(\mathrm{C}_{1}\right)\left(\mathrm{C}_{2}\right)+\mathrm{a}\right)\left(\mathrm{U}_{\mathrm{e} 2}\right)\left(\mathrm{V}_{\mathrm{P}-\mathrm{G}}\right)\right]
$$

Where $\mathrm{C}_{2}$ is composed from a supplementary contribution taking in account the line working tools in the air gap (6\%) plus additional (4\%) for intangibles. This supplement is however variable and can vary between $2 \%$ and $20 \%$ according to the structure and the electrode configuration. For the calculations, a value of $\mathrm{C}_{2}$ equal to 1,1 is used in [5].

\section{Paris \& Galey-Leroy Formulas}

Several researchers demonstrated that the discharge voltage in air for positive polarity $\left(\mathrm{U}_{50}\right)$, in different structures for intervals from 2 to $8 \mathrm{~m}$, follows the following expression [8]:

$$
\mathrm{U}_{50}=\mathrm{K}_{1} 500 . \mathrm{Du}^{0.6}
$$

Where $\mathrm{Du}$ is the gap distance in meters and $\mathrm{K}_{1}$ a gap factor related to the electrodes geometry.

For a rod-plane configuration, the factor $K_{1}=1$. Thus, this factor represents a proportionality factor of $U_{50}$, where $K_{1}$ $=\mathrm{U}_{50} / \mathrm{U}_{50}$ rod-plane.

\section{Atlani Formula [10]}

In this method, the expression of the minimum approach distance is simplified to:

$$
\mathrm{D}_{\mathrm{A}}=\mathrm{D}_{\mathrm{U}}+\mathrm{D}_{\mathrm{E}}
$$

With Un $=200 \mathrm{Du}$

Where $\mathrm{Du}$ is the electric distance in meters and Un the nominal voltage in $\mathrm{kV}$.

The distance $\mathrm{D}_{\mathrm{E}}$, in meters, is taken equal to:

$* 0.30 \mathrm{~m}$ for low voltages.

$* 0.50 \mathrm{~m}$ for high voltages.

\section{Variations of the Characteristic $U_{50}=f(D u)$}

The analytical calculation achieved for different voltage levels and geometric configurations with the different formulas for normal conditions gives the curves represented in figure 2.

From this figure reassembling the results of the analytic survey, one notices that for the same discharge voltage level $\mathrm{U}_{50}$ tension, the IEC 61-472 standard foresees the most important electric distance $(\mathrm{Du})$ with regard to other standards and formulas. On the other hand, the distance $\mathrm{Du}$ ) obtained by Paris formula is the weakest. One notes that the IEC standard considers a more elevated security factor [11].

From this survey, one can also summarise that the IEC standard takes in account several factors that intervene in the calculation of the electric distance (Du), what permitted to obtain a more important distance with regard to other standards. 


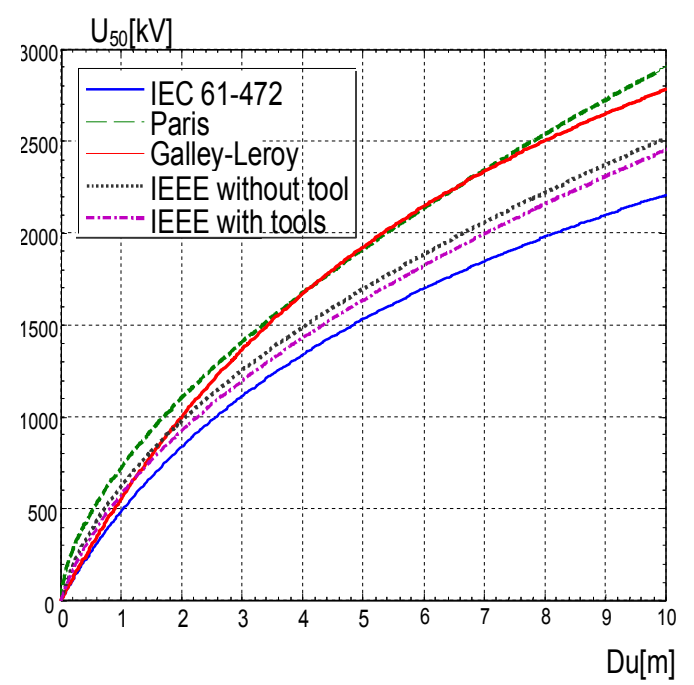

Figure 2. Variations of $\mathrm{U}_{50}=\mathrm{f}(\mathrm{Du})$ from different formulas (IEC 61-472, Paris, Galley-Leroy and IEEE Std 516, With and without tools).

\section{Comparative Survey Between the Different Standards With Regard to the Electric Field Emax.}

The variation law of the breakdown electric field as a function of the voltage and the critical distance, for a tip of normalized radius of $6.25 \mathrm{~mm}$, is applicable for the different standards, and the obtained results by FEMM software are closer with regard to Emax (Figure 3), except the Paris formula that gives important disruptive field values. It is owed to the minimum approach distance calculated with this formula.

\section{Relation between the Radius of Curvature $r_{p}$ and the Minimum Approach Distance.}

\section{A. Relationship between the electric field and the minimum approach distance.}

The commonly used methods of determination of the minimum approach distances consider stressed tools or bodies of rounded shape of radius superior or equal to $6.25 \mathrm{~mm}$.

The MAD depends essentially on the voltage level that reigns in the area where a live work should be executed. This dependence is reported in [11] where both electric field and minimum approach distance evolve in the same way when the voltage is varied.

On the other hand, the MAD depends on the shape of the tools that the operator can use, that can be of lower radius than the normalised ones if special action is required. Hence, the best parameter that can control the safe approach distance is the max electric field that can be present in the vivacious area of work instead of the applied voltage. Figure 4 presents the variations of the MAD as a function of the max electric field. The MAD will be more important than the electric field is increased. The variation is not linear; it obeys to an empirical $3^{\text {rd }}$ order polynomial relation with a determination coefficient $\mathrm{R}^{2}=0.999$ :
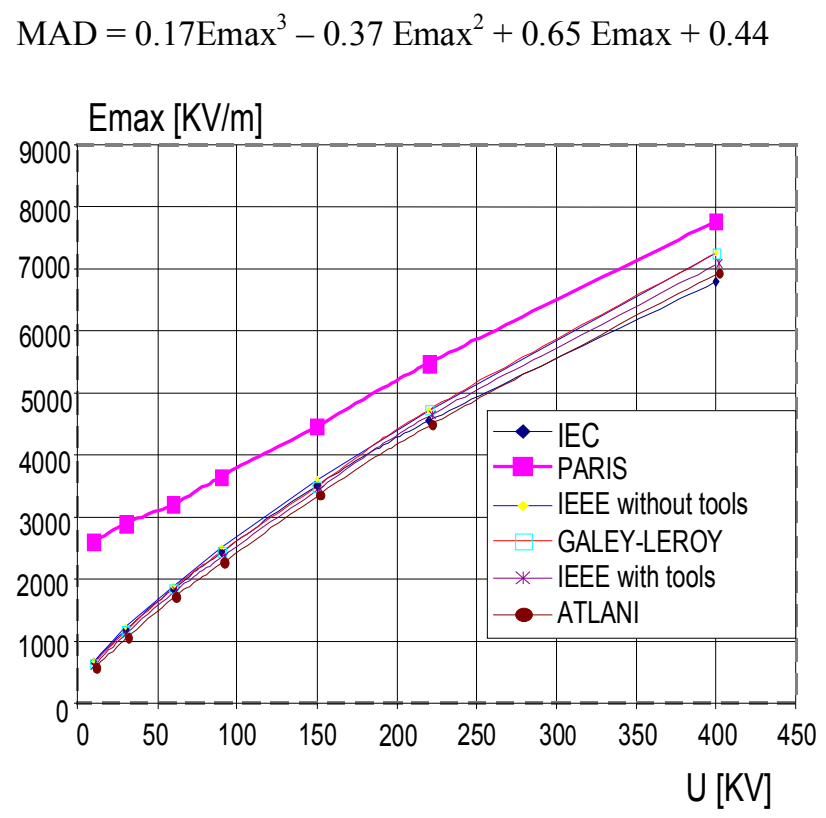

Fig. 3. Variations of the max electric field as a function of the voltage for a point of normalised radius of $6.25 \mathrm{~mm}$, according to different standards and authors.

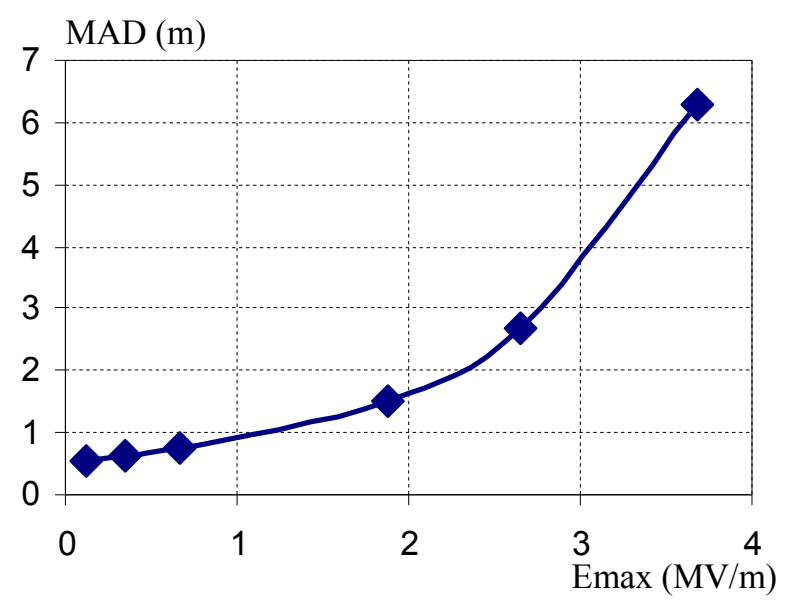

Fig.4. Variations of the MAD (m) as a function of the max field Emax $(\mathrm{MV} / \mathrm{m})$ (from IEC) determined for a point of normalized radius of $6,25 \mathrm{~mm}$

\section{B. Influence of the radius of curvature on the MAD: Numerical method.}

The electric field being dependent of the radius of curvature of the used tool, we determined for each voltage level, a relation of dependence that should link the MAD to the radius of curvature.

By varying the radius of the rod tip for different voltage levels, and in parallel, one acts on the electrode gap until to have an equal maximal field to the one reported in figure 4, we can accede to the variations of the MAD as a function of the radius of curvature of the working tools. They are illustrated on figure 5 .

Thus, we developed a method that consists in using the numerical techniques in the aim to adapt the empirical methods for the assessment of the minimal approach distances when tools of work of non conventional dimensions are used. The obtained results show that the 
MAD must be much more important than the tools radius is small. However, this importance becomes insignificant for radiuses greater than $20 \mathrm{~mm}$.

On the same figure, are also reported the values of the MAD corresponding to the considered voltages, obtained after interpolations in equation 4. A good agreement is found between these values, for the considered conditions, and those obtained according to IEC 61-472 for an altitude of $200 \mathrm{~m}$ and a per unit factor of transient overvoltage $\mathrm{u}_{\mathrm{e} 2}=2.2$. The most important deviation is $1.32 \%$ (corresponding to $3.1 \mathrm{~cm}$ ) that is lower than the difference between the values generally considered for the ergonomic distances relative to involuntary movements (30 cm for IEEE Std 516 and $50 \mathrm{~cm}$ for IEC 61-472).

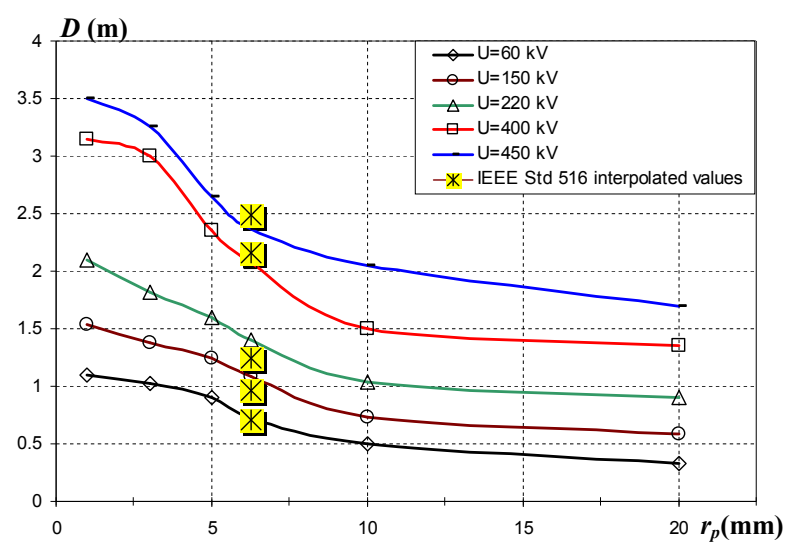

Fig. 5. Minimum approach distance $D$ vs. curvature radius $r p$ of the point, in rod-plane electrode system.

\section{Conclusion}

The applied voltage level remains the most decisive element concerning the electric field height and the dimension of the MAD to be respected by operators. Moreover, the dimensions of the equipments and tools used while performing live works play an important role on the local strengthening of the electric field and so on the dimensioning of the MAD.

The results obtained by numeric method are in good agreement with those obtained by analytic calculation. In table 4 are reported the variations of the minimum electric distance (Du) for fixed voltage level and radius of curvature. The validation of these results by experimental measurements would lead to news empirical relations. This is our contribution for the dimensioning of security distances while live works have to be executed.

\section{References}

[1] G. Gela, Live working and maintenance techniques, CIGRE 2000, P1-03.

[2] L. Thione, An overview of live working and maintenance techniques, CIGRE 2000, P1-01.

[3] N. Baljepali, S.S. Venkata, C.W.Jr. Richter, R.D. Christie \& V.J. Longo, Distribution system reliability assessment due to lightning storms, IEEE Trans. On Power Delivery, Vol. 20, Issue 3, July 2005, 2153-2159.

[4] L. Thione, An overview of live line diagnostic techniques, CIGRE 2000, P1-02.
[5] IEEE Guide for maintenance methods on energized power lines, Std 516, 2003.

[6] IEC 61-472, Live Working - Minimum Approach Distances - Method of Calculation, 1998, 10-27.

[7] E Kuffel, W S Zaengl and J Kuffel, 'High voltage engineering fundamentals" Newnes, ButterworthHeinemann, Second Edition 2000, p.481

[8] IEEE Standard Techniques for High Voltage Testing, Std 41995.

[9] M. Aguet \& M. Ianoz, Traité d'électricité - Haute tension, Vol XXII (Lausanne, Switzerland: Publication des presses polytechniques et universitaires romandes, 2001) 391-392.

[10] C. Atlani, Travaux sous tension, Techniques de l'Ingénieur, D4 140, 1 - 9 .

[11] H. Moulai, S. Belkhir and F. Soukeur, " Electric Field Assessment in High Volatage Systems: Application to Live Worrking on Overhead Lines.", $5^{\text {th }}$ International conférence on Power and Energy Systerms ''EUROPES 05", IASTED, 15-17 June 2005, BENALMADENA, MALAGA, SPAIN. 